\title{
Efficacy of selective plasma exchange as pre-transplant apheresis in ABO- incompatible kidney transplantation
}

Ako Hanaoka ${ }^{1}$, Toshihide Naganuma ${ }^{2}$, Yoshiaki Takemoto ${ }^{2}$, Junji Uchida ${ }^{2}$, Tatsuya Nakatani ${ }^{2}$, Daijiro Kabata ${ }^{3}$ and Ayumi Shintani ${ }^{3}$

\begin{abstract}
Background: Selective plasma exchange (SePE) is a new simple plasma exchange (PE) modality that enables removal of small and medium-sized molecules without removing larger substances such as coagulation factors. In this study, we examined the efficacy of SePE for removal of isoagglutinins in pre-transplant desensitization for ABO-incompatible (ABOi) kidney transplantation.

Materials and methods: A case series study was performed in 15 ABOi kidney transplant recipients (KTRs) who underwent SePE alone (7 cases) and SePE in combination with double-filtration plasmapheresis or simple plasma exchange (8 cases). The target processed plasma volume (PV) was set at $2 \mathrm{PV}$, and $5 \%$ albumin solution was used as the substitution fluid in all SePE sessions. Changes in isoagglutinin titers (IgG and IgM) and serum $\operatorname{lgG}$, IgM, and fibrinogen levels were examined. We also compared the decrease in isoagglutinin titers between SePE and conventional methods (PE and double-filtration plasmapheresis).

Results: A total of 29 sessions of SePE were performed in the $15 \mathrm{KTRs}$. Isoagglutinin titers were controlled to $\leq 1: 16$ in all patients except for 2 with high isoagglutinin titers, and there were no cases of antibody-mediated rejection. SePE led to a median twofold decrease in isoagglutinin titers (IgG and $\operatorname{lgM}$ ), with median IgG, IgM, and fibrinogen removal rates of $64.2,11.7$, and $25.5 \%$, respectively. Side effects occurred in only 4 of the 29 sessions. Neither titer decreased after SePE in $30 \%$ of the sessions. However, the reductions in isoagglutinin titers in patients undergoing SePE were significantly less than those in patients treated with conventional methods.

Conclusion: Because SePE is less efficient in removing isoagglutinins compared to conventional methods, the use of SePE alone should be limited to patients with low isoagglutinin titers, and SePE in combination with conventional methods should be used for patients with high isoagglutinin titers. SePE may be a useful treatment option, if applied in appropriate cases, due to its lower cost (about half the price of PE using fresh frozen plasma in Japan) and fewer side effects. However, care is required because about 25\% of fibrinogen is removed during SePE.
\end{abstract}

Keywords: Kidney transplantation, Selective plasma exchange, Apheresis, ABO-incompatible

\footnotetext{
* Correspondence: spxd48k9@aria.ocn.ne.jp

2Department of Urology, Osaka City University Graduate School of Medicine,

1-4-3 Asahi-machi, Abeno-ku, Osaka 545-8585, Japan

Full list of author information is available at the end of the article
}

(c) The Author(s). 2019 Open Access This article is distributed under the terms of the Creative Commons Attribution 4.0 International License (http://creativecommons.org/licenses/by/4.0/), which permits unrestricted use, distribution, and reproduction in any medium, provided you give appropriate credit to the original author(s) and the source, provide a link to the Creative Commons license, and indicate if changes were made. The Creative Commons Public Domain Dedication waiver (http://creativecommons.org/publicdomain/zero/1.0/) applies to the data made available in this article, unless otherwise stated. 


\section{Introduction}

Recently, pre-transplant apheresis is less frequently being performed in ABO-incompatible (ABOi) kidney transplantation for patients with already low isoagglutinin titers or those successfully desensitized by immunosuppressants such as rituximab [1-6]. However, multiple sessions of apheresis are still performed at many institutions for isoagglutinin removal in pre-transplant desensitization for ABOi kidney transplantation [7-11]. Double-filtration plasmapheresis (DFPP), simple plasma exchange (PE), and antigen-specific immunoadsorption (IA) are also often performed as methods of apheresis in ABOi kidney transplantation [12-14].

Repeated DFPP or PE (using albumin solution as substitution fluid) can cause a marked loss in coagulation factors $[15,16]$, which can then cause perioperative bleeding, especially if the last session was performed on the day before the transplant [17]. With PE, there have been reports of treatment being suspended due to side effects such as allergic reactions to fresh frozen plasma (FFP) [18, 19]. This is particularly disadvantageous for hemodialysis (HD) and apheresis combination therapy because both apheresis and HD may have to be discontinued due to allergic reactions. Antigen-specific IA using Glycosorb ${ }^{\oplus}$-ABO columns is a useful method that causes fewer side effects without removing coagulation factors, but the columns cost about 3000 euro each [13]. Moreover, the use of this column has not been approved in Japan.

Selective plasma exchange (SePE) is a new simple PE modality that uses a membrane plasma separator with a smaller pore size compared to conventional plasma separators and enables removal of small and medium-sized molecules without removing larger substances such as coagulation factors [20]. SePE has increasingly been reported as an effective method in cases where the etiologic agent can be removed [21-24], since it exhibits fewer side effects through the use of albumin as the substitution fluid, in contrast to the use of FFP in PE. SePE also has a cost benefit because albumin is cheaper than FFP. SePE is about half the price of PE using FFP in Japan. However, a disadvantage of SePE is that it is less effective in removing relatively larger molecules, and SePE requires a greater volume of substitution fluid compared with regular PE [20]. In this study, we examined the efficacy of SePE for removal if isoagglutinins in pre-transplant desensitization for ABOi kidney transplantation.

\section{Patients and methods}

\section{Study design and participants}

A retrospective, case series study was conducted in patients with end-stage renal disease who underwent ABOi kidney transplantation with apheresis therapy from January 2015 to December 2017 at Osaka City University Hospital. The inclusion criteria were kidney transplant recipients (KTRs) who had undergone at least one session of SePE. Patients with donor-specific antibodies were excluded. A total of $15 \mathrm{KTRs}$ were enrolled in the study.

This study protocol was conducted in accordance with the Principles of the Declaration of Helsinki and the Declaration of Istanbul and was approved by the ethics committee of the Osaka City University Graduate School of Medicine (No. 4009). Opt-out consent was obtained instead of written informed consent; i.e., we provided the patients with information explaining the proposed research project (the purpose, required individual data, and duration of the study) by means of an information sheet or hospital website and gave them the opportunity to opt out. The demographic and baseline clinical data are presented in Table 1.

\section{Desensitization protocols}

Desensitization was conducted by immunosuppressive therapy, centering on rituximab, and apheresis to reduce the pre-transplant isoagglutinin titers (immunoglobulin G (IgG) and IgM) to $\leq 1: 16$ [8, 25-27].

1. Immunosuppression protocols $[4,28]$ : The pretransplant desensitization regimen included 4 weeks of mycophenolate mofetil (MMF; $1 \mathrm{~g} /$ day). Patients aged $\geq 65$ years old underwent treatment with $0.5 \mathrm{~g} /$ day MMF for 4 weeks. Almost all patients with titers $<1: 512$ underwent treatment with a single dose of rituximab $\left(150 \mathrm{mg} / \mathrm{m}^{2}\right) 2$ weeks before transplantation. Patients with titers $>1: 512$, rebound of antibody titers, or donor-specific antibodies underwent both splenectomy at transplantation and treatment with two doses of rituximab $\left(150 \mathrm{mg} / \mathrm{m}^{2}\right) 2$ weeks before and on the day of transplantation. Post-transplant immunosuppression consisted of a calcineurin inhibitor (tacrolimus or cyclosporine, initiated 3 days prior to transplantation), MMF or everolimus, steroids, and two doses of basiliximab.

2. Apheresis protocols: For removal of isoagglutinins, patients underwent 1 to 13 sessions (at least 1 session) of apheresis (PE, DFPP, SePE) before transplantation until isoagglutinin titers decreased to $<1: 16$. In earlier cases (cases 1 and 2), SePE was performed in patients with high titers. However, after we learned that this procedure was not as effective as DFPP and PE in reducing isoagglutinin titers, SePE was performed after the isoagglutinin titers were reduced to some extent by DFPP or PE in patients with high titers (>1:64). Currently, SePE alone is performed once or twice in patients with isoagglutinin titers $<1: 32$. 
Table 1 Characteristics and results of the study subjects

\begin{tabular}{|c|c|c|c|c|c|c|c|c|c|c|c|c|}
\hline \multirow[t]{2}{*}{ Case } & \multirow[t]{2}{*}{ Order and frequency of apheresis including SePE } & \multirow[t]{2}{*}{$\begin{array}{l}\text { SePE } \\
+\mathrm{HD}\end{array}$} & \multirow[t]{2}{*}{$\begin{array}{l}\text { Sex/ } \\
\text { age }\end{array}$} & \multirow{2}{*}{$\begin{array}{l}\text { Donor } \\
\text { (sex/ } \\
\text { age) }\end{array}$} & \multirow[t]{2}{*}{ Relationship } & \multirow[t]{2}{*}{$\begin{array}{l}\text { Blood } \\
\text { type }\end{array}$} & \multicolumn{3}{|c|}{$\begin{array}{l}\text { Isoagglutinin titers } \\
(\operatorname{lgG})\end{array}$} & \multicolumn{3}{|c|}{$\begin{array}{l}\text { Isoagglutinin } \\
\text { titers (IgM) }\end{array}$} \\
\hline & & & & & & & Base & At $T x$ & Max & Base & $\begin{array}{l}\text { At } \\
\text { Tx }\end{array}$ & $\operatorname{Max}$ \\
\hline 1 & DFPPX1 $\rightarrow$ SePEx6 & No & $\begin{array}{l}M / \\
67\end{array}$ & $F / 66$ & Spouse & $\begin{array}{l}\mathrm{AB}+\rightarrow \\
\mathrm{O}+\end{array}$ & $\begin{array}{l}256 / \\
256\end{array}$ & $\begin{array}{l}32 / \\
128\end{array}$ & $\begin{array}{l}256 / \\
256\end{array}$ & $\begin{array}{l}16 / \\
16\end{array}$ & $8 / 8$ & $\begin{array}{l}16 / \\
16\end{array}$ \\
\hline 2 & $\begin{array}{l}\mathrm{SePEX} 2 \rightarrow \mathrm{PE}(\mathrm{f}) \times 1 \rightarrow \mathrm{PE}(\mathrm{a}) \times 1 \rightarrow \mathrm{PE}(\mathrm{f}) \times 1 \rightarrow \\
\mathrm{DFPP} \times 1 \rightarrow \mathrm{PE}(\mathrm{a}) \times 7\end{array}$ & Yes & $\mathrm{F} / 60$ & $M / 58$ & Spouse & $\begin{array}{l}\mathrm{B}+\rightarrow \mathrm{O} \\
+\end{array}$ & 1024 & 64 & 1024 & 512 & 1 & 1024 \\
\hline 3 & $\mathrm{DFPP} \times 1 \rightarrow \mathrm{PE}(\mathrm{f}) \times 1 \rightarrow \mathrm{SePE} \times 1$ & Yes & $F / 64$ & $M / 59$ & Spouse & $\mathrm{A}+\rightarrow \mathrm{B}+$ & 16 & 8 & 32 & 16 & 2 & 16 \\
\hline 4 & DFPPX2 $\rightarrow$ SePEx 1 & Yes & $F / 32$ & $M / 55$ & Parent & $\begin{array}{l}\mathrm{AB}+\rightarrow \mathrm{B} \\
+\end{array}$ & 8 & 1 & 16 & 8 & 1 & 16 \\
\hline 5 & $\mathrm{DFPP} \times 1 \rightarrow \mathrm{PE}(\mathrm{a}) \times 1 \rightarrow \mathrm{DFPP} \times 1 \rightarrow \mathrm{SePE} \times 1$ & Yes & $F / 39$ & $M / 61$ & Parent & $\begin{array}{l}\mathrm{B}+\rightarrow \mathrm{O} \\
+\end{array}$ & 256 & 4 & 256 & 32 & 2 & 32 \\
\hline 6 & DFPPx2 $\rightarrow$ SePEx 1 & No & $\begin{array}{l}M / \\
44\end{array}$ & $F / 67$ & Parent & $\begin{array}{l}\mathrm{B}+\rightarrow \mathrm{O} \\
+\end{array}$ & 64 & 8 & 64 & 32 & 2 & 32 \\
\hline 7 & DFPPx2 $\rightarrow$ SePEx 1 & No & $F / 69$ & M/69 & Spouse & $\begin{array}{l}\mathrm{AB}+\rightarrow \mathrm{B} \\
+\end{array}$ & 16 & $<1$ & 16 & 16 & 1 & 16 \\
\hline 8 & SePEX2 & Yes & $F / 44$ & $F / 48$ & Sibling & $\mathrm{B}+\rightarrow \mathrm{A}+$ & 1 & $<1$ & 1 & 2 & 1 & 2 \\
\hline 9 & SePEx2 & Yes & $\begin{array}{l}M / \\
52\end{array}$ & $\mathrm{~F} / 50$ & Spouse & $\mathrm{B}+\rightarrow \mathrm{A}+$ & 4 & 1 & 4 & 4 & 1 & 4 \\
\hline 10 & SePEx2 & Yes & $\begin{array}{l}M / \\
53\end{array}$ & $F / 49$ & Parent & $\mathrm{B}+\rightarrow \mathrm{A}+$ & 8 & 2 & 16 & 4 & 2 & 8 \\
\hline 11 & SePEx2 & Yes & $\begin{array}{l}M / \\
53\end{array}$ & $\mathrm{~F} / 50$ & Spouse & $\mathrm{B}+\rightarrow \mathrm{A}+$ & 8 & 2 & 8 & 4 & 4 & 4 \\
\hline 12 & SePEx2 & Yes & $\begin{array}{l}M / \\
53\end{array}$ & $F / 55$ & Spouse & $\mathrm{B}+\rightarrow \mathrm{A}+$ & 2 & 1 & 1 & 2 & 1 & 2 \\
\hline 13 & $\mathrm{PE}(\mathrm{f}) \times 1 \rightarrow \operatorname{SePEx} 3$ & No & $\begin{array}{l}M / \\
51\end{array}$ & $\mathrm{~F} / 50$ & Spouse & $\mathrm{A}+\rightarrow \mathrm{B}+$ & 32 & 1 & 32 & 32 & 1 & 32 \\
\hline 14 & SePEx2 & No & $\begin{array}{l}M / \\
37\end{array}$ & $M / 39$ & Spouse & $\mathrm{A}+\rightarrow \mathrm{B}+$ & 16 & 8 & 32 & 8 & 4 & 32 \\
\hline 15 & SePEx1 & No & $\begin{array}{l}M / \\
53\end{array}$ & $M / 55$ & Sibling & $\mathrm{B}+\rightarrow \mathrm{A}+$ & 16 & 8 & 16 & 16 & 8 & 16 \\
\hline
\end{tabular}

SePE selective plasma exchange, DFPP double-filtration plasmapheresis, $P E$ ( $f$ ) simple plasma exchange using fresh frozen plasma as the substitution fluid, $P E$ ( $a$ ) simple plasma exchange using $5 \%$ albumin solution as the substitution fluid, $H D$ hemodialysis, $M$ male, $F$ female, $I g G$ immunoglobulin $G$, $I g M$ immunoglobulin $M$, Tx kidney transplantation

\section{Conditions for performing SePE (Fig. 1)}

Plasmapheresis therapies were performed using a KM-9000 (Sanyo Electronic Industries Co., Ltd. Okayama, Japan) or TR55X (Toray Medical Co., Ltd. Tokyo, Japan) blood purification system. SePE was performed using an Evacure Plus EC-4A10 (Evaclio, EC-4C in overseas model) (Kawasumi Laboratories, Inc., Tokyo, Japan) selective plasma separator [29]. The volumes used for priming the circuit were about $370 \mathrm{~mL}$ in SePE (about $320 \mathrm{~mL}$ in PE). Albumin solution (5\%) was used as the substitution fluid in all SePE sessions. During SePE, blood flow was maintained at $100 \mathrm{ml} / \mathrm{min}$ with a plasma separation rate of $30 \mathrm{ml} / \mathrm{min}$, and unfractionated heparin or nafamostat mesilate was used as the anticoagulant. Plasma volume (PV) was calculated using the following equation [30]: $\mathrm{PV}=(\mathrm{BW} / 13) \times(100-\mathrm{Ht}) / 100$, where $\mathrm{BW}$ and $\mathrm{Ht}$ indicate body weight $(\mathrm{kg})$ and hematocrit (\%), respectively. The target processed PV was set at $2 \mathrm{PV}$. In tandem $\mathrm{HD}$ and SePE, SePE was performed in parallel with the HD circuit, with a blood flow rate of $100 \mathrm{~mL} / \mathrm{min}$ into the SePE circuit (Fig. 1). The cost of SePE using $2 \mathrm{PV} 5 \%$ albumin solution is about half the price of PE using 1.5 PV FFP.

\section{Measurement of clinical data}

Isoagglutinin titers were measured by the tube centrifugation test, anti-A/B IgM titers were determined using the saline agglutination technique, and IgG titers were evaluated using the indirect Coombs test. Changes in isoagglutinin titers and serum IgG, IgM, and fibrinogen levels were studied, in addition to any adverse effects. The removal rates (RR) of IgG, IgM, and fibrinogen were corrected for the change in hematocrit $(\mathrm{Ht})$ with the change in colloid osmotic pressure, using the following equation [30]: RR = [1-pre Ht (1-post Ht/100) post-conc/ post $\mathrm{Ht}(1$-pre $\mathrm{Ht} / 100)$ pre-conc] $\times 100$, where pre $\mathrm{Ht}$ and post $\mathrm{Ht}$ indicate hematocrit (\%) before and immediately after apheresis, respectively. 


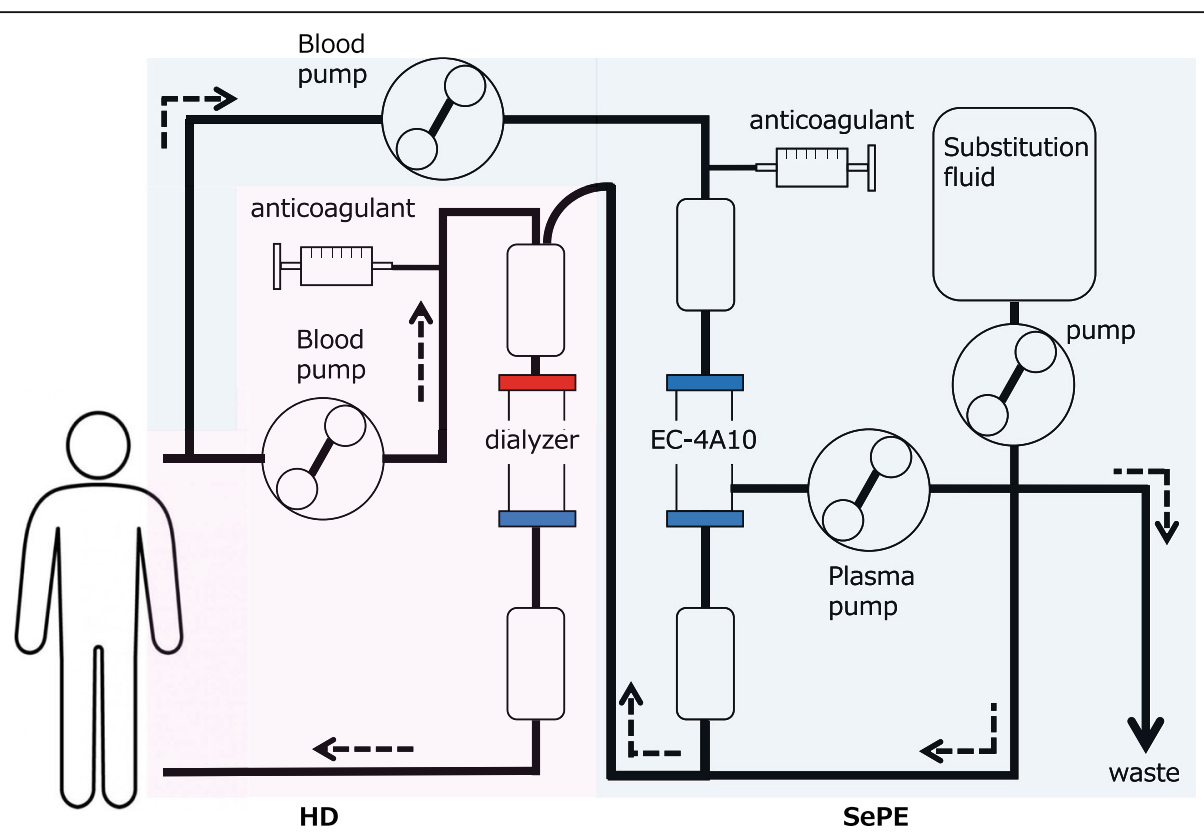

Fig. 1 Selective plasma exchange circuit with hemodialysis

\section{Statistical analysis}

Baseline demographic and clinical characteristics are summarized as the median and interquartile range for continuous variables and counts and percentage for categorical variables. In order to examine the effect of SePE on the isoagglutinin titers change rates, multivariable proportional odds ordinal logistic regression models were used with IgG and IgM as independent variables, separately. In these models, baseline values of isoagglutinin titers were adjusted. In the analysis, changes in isoagglutinin titers were counted individually for anti-A and anti-B in case 1 because the kidney was transplanted from $A B$ $+\rightarrow \mathrm{O}+$. All statistical analyses were two-sided with a $5 \%$ significance level and were performed using $\mathrm{R}$ version 3.3.2 (https://www.r-project.org/foundation/) with the "rms" and "RcmdrPlugin.EZR" packages.

\section{Results}

\section{Characteristics of subjects (Table 1)}

A total of 29 sessions of SePE were performed in 15 KTRs, including SePE alone (7 KTRs) and SePE in combination with DFPP or PE (8 KTRs). HD and SePE combination therapy was performed in 9 KTRs and SePE monotherapy was performed in 6 KTRs (3 peritoneal dialysis and 3 preemptive kidney transplantation). Isoagglutinin titers were controlled to $\leq 1: 16$ in all except 2
KTRs with high titers (cases 1 and 2, who also underwent splenectomy) before transplantation, and there were no cases of antibody-mediated rejection. There were two cases of acute rejection (case 6 and case 9, 13.3\%). Side effects occurred in 4 of the 29 sessions, including general ill feeling and hot flashes in case 1 , nausea and hypotension in case 4 , epigastric distress in case 8 , and leg cramps in case 15. No circuit coagulation occurred in all sessions. All were considered to be minor side effects and were improved by symptomatic treatment.

\section{Median decrease and removal rate by SePE (Table 2)}

There was a median twofold decrease in isoagglutinin titers (IgG and IgM) by SePE. The median removal rates (\%) of IgG, IgM, and fibrinogen were 64.2 [60.1-68.1], 11.7 [8.3-18.3], and 25.5 [18.0-32.2] \%, respectively.

\section{Comparison of the reduction volumes distribution in isoagglutinin titers between SePE and conventional methods (PE, DFPP) (Figs. 2 and 3)}

The reduction in isoagglutinin titers was compared between SePE (29 sessions) and conventional methods (4 sessions of PE using FFP, 9 sessions of PE using 5\% albumin solution, and 11 sessions of DFPP). The distribution of reductions in isoagglutinin titers (IgG and IgM) with each modality are shown in Figs. 2 and 3, respectively.

Table 2 Median decrease and removal rate of clinical data by SePE

\begin{tabular}{lllll}
\hline Isoagglutinin titers $(\operatorname{lgG})$ & Isoagglutinin titers $(\operatorname{lgM})$ & $\operatorname{lgG}$ & Fibrinogen \\
\hline$\times 2$ & $\times 2$ & $64.2 \%$ & $11.7 \%$ & $25.5 \%$ \\
\hline
\end{tabular}

SePE selective plasma exchange, $\lg G$ immunoglobulin $\mathrm{G}$, $\lg M$ immunoglobulin $\mathrm{M}$ 


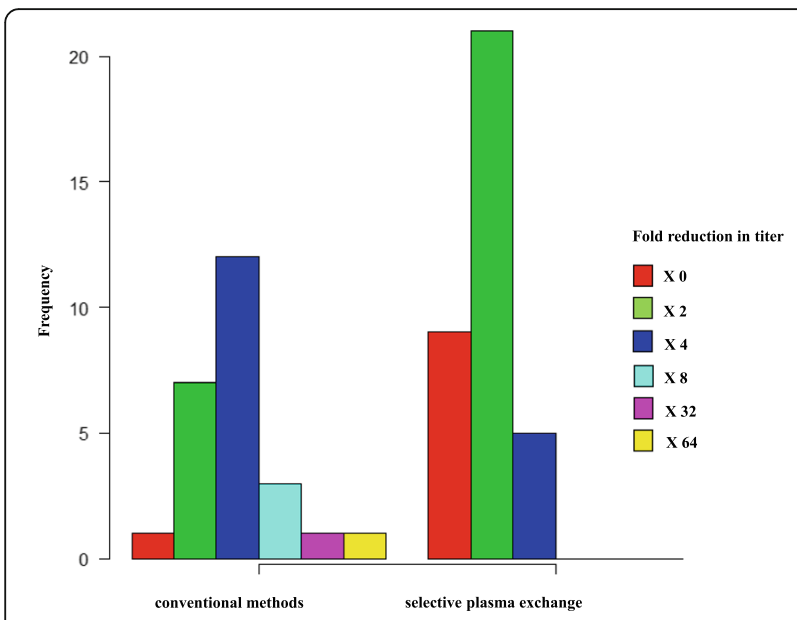

Fig. 2 Comparison of the reduction volumes distribution in isoagglutinin titers between SePE and conventional methods (lgG)

Neither titer decreased after SePE in about 30\% of the sessions (IgG; 10/29, IgM; 9/29).

Comparison of the reduction volumes in anti-blood group antibody titers between SePE and conventional methods (PE, DFPP) (Table 3).

The reduction volumes of isoagglutinin titers of patients with $\operatorname{SePE}(n=29)$ were significantly less than those of patients with conventional methods (PE, DFPP) $(n=25)(P<0.001$ for both IgG and IgM).

\section{Discussion}

Since 2015, we have performed SePE as an apheresis modality for ABOi kidney transplantation. In $29 \mathrm{SePE}$ sessions performed in 15 KTRs without any incidence of antibody-mediated rejection, we were able to control isoagglutinin titers (IgG, IgM) to $\leq 1: 16$ [8, 25-27] in all except 2 KTRs with high antibody titers. There was a median twofold decrease in isoagglutinin titers in our patients undergoing SePE. The median removal rate of fibrinogen was $25.5 \%$. Side effects occurred in only 4 of the 29 sessions. However, the reduction in isoagglutinin titers in patients undergoing SePE was significantly less than that in patients treated with conventional methods. This study is the first report of the use of SePE for isoagglutinin removal in pre-transplant desensitization for ABOi kidney transplantation.

Initially, we performed SePE in KTRs with high isoagglutinin levels, but we found that this was not as effective as conventional methods (PE, DFPP) for removal of

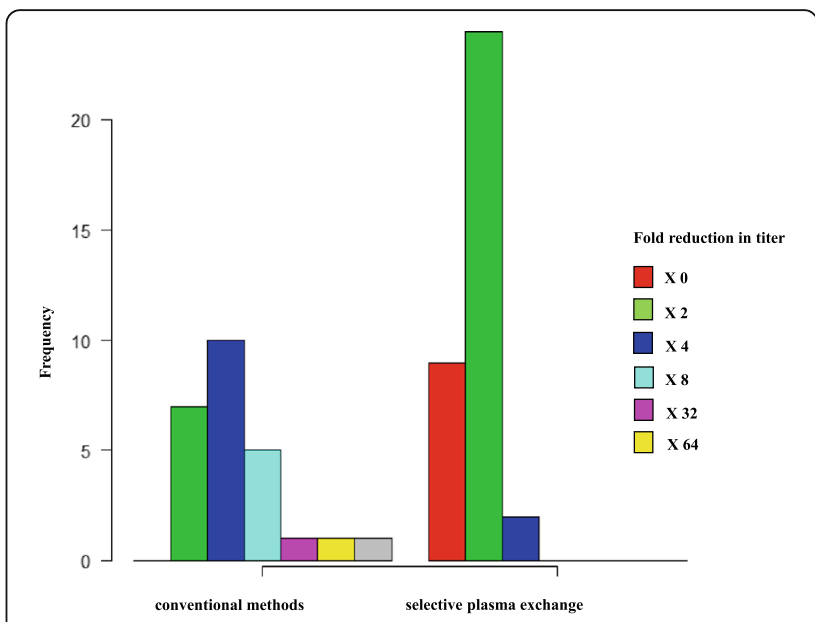

Fig. 3 Comparison of the reduction volumes distribution in isoagglutinin titers between SePE and conventional methods (IgM)

isoagglutinins, even when using $2 \mathrm{PV}$ of substitution fluid (cases 1 and 2). Therefore, we subsequently decided to first perform DFPP or PE in KTRs with high isoagglutinin levels, followed by SePE after these levels were reduced sufficiently. A median twofold decrease in isoagglutinin titers was obtained using SePE (Table 2), but the titers did not decrease at all in 30\% of the sessions (Figs. 2 and 3) and the reduction in isoagglutinin titers in SePE was significantly less than that with conventional methods (Table 3). These results suggest that SePE alone is sufficient for KTRs with isoagglutinin titers $\leq 1: 32$, but in KTRs with titers $\geq 1: 64$, it is preferable to first perform PE or DFPP and decrease isoagglutinin to $\leq 1: 32$ before performing SePE.

The sieving coefficient of IgM was 0 , according to the manufacturer's reported value for Evacure Plus EC-4A10 [20], and the actual removal rate was approximately $10 \%$, with the isoagglutinin $(\operatorname{IgM})$ titers decreasing in the same manner as the isoagglutinin (IgG) titers (Figs. 2 and 3). This may have been caused by adsorption to the membrane, but the precise mechanism remains unclear.

Regarding coagulation factors, although the sieving coefficient of fibrinogen is reported to be 0 [20], the actual removal rate was about $25 \%$. Based on scanning electron microscopy imaging, Ohkubo et al. [31] found that fibrinogen reduction by SePE using EC-4A10 is due to membrane fouling by substances such as fibrinogen fibrils. When DFPP is performed repeatedly, the fibrinogen levels decrease considerably $[15,16]$, such that $25 \%$

Table 3 Comparison of decrease volumes in isoagglutinin titers between SePE and conventional methods (PE, DFPP)

\begin{tabular}{|c|c|c|c|c|}
\hline \multirow[t]{2}{*}{ Variable } & \multicolumn{2}{|l|}{$\lg G$ titers } & \multicolumn{2}{|l|}{ lgM titers } \\
\hline & Odds ratio $(95 \% \mathrm{Cl})$ & $P$ value & Odds ratio $(95 \% \mathrm{Cl})$ & $P$ value \\
\hline SePE or not & $0.059(0.017-0.205)$ & $P<0.0001$ & $0.014(0.002-0.091)$ & $P<0.0001$ \\
\hline
\end{tabular}

These odds ratios and $P$ values were adjusted for pre-isoagglutinin titers. SePE selective plasma exchange, $P E$ simple plasma exchange, $D F P P$ double-filtration plasmapheresis, IgG immunoglobulin $\mathrm{G}$, IgM immunoglobulin $\mathrm{M}, \mathrm{Cl}$ confidential interval 
removal by SePE becomes disadvantageous. In such cases, aggressive FFP transfusions are desirable.

With respect to side effects, we were able to perform SePE safely with only a few minor side effects, due to the use of albumin rather than FFP $[18,19]$. In addition, because $5 \%$ albumin solution was used, there were few incidences of hypotension, even though fluid removal was performed in tandem with HD.

The study has some limitations. First, our sample size was small and there was no control group, and a further study with a larger sample size and a control group is needed to confirm the results. Second, with respect to the graft function, investigation of the long-term impact of this protocol may be necessary. Third, further studies are needed to compare the therapeutic efficacy of SePE monotherapy with conventional methods (PE, DFPP, IA).

In conclusion, because SePE is less efficient in removing isoagglutinins compared to conventional methods, the use of SePE alone should be limited to patients with low isoagglutinin titers, and SePE in combination with conventional methods should be used for patients with high isoagglutinin titers. SePE may be a useful treatment option, if applied in appropriate cases, due to its lower cost (about half the price of PE using fresh frozen plasma in Japan) and fewer side effects. However, care is required with the use of SePE because about $25 \%$ of fibrinogen is removed.

\section{Abbreviations}

ABO-i: ABO-incompatible; DFPP: Double-filtration plasmapheresis; FFP: Fresh frozen plasma; HD: Hemodialysis; Ht: Hematocrit; IA: Immunoadsorption; KTRs: Kidney transplant recipients; MMF: Mycophenolate mofetil; PE: Simple plasma exchange; PV: Plasma volume; RR: Removal rates; SePE: Selective plasma exchange

\section{Acknowledgements}

Not applicable.

\section{Funding}

The authors declare that there is no funding related to this manuscript.

\section{Availability of data and materials}

The data and materials were all included in the manuscript.

\section{Authors' contributions}

A.H. (first author) and T.N. (corresponding author) contributed to the concept, design, data acquisition, interpretation, and writing. D.K. and A.S. contributed to the data analysis and interpretation. Y.T., U.J., and T.N. reviewed and revised the manuscript. All authors read and approved the final manuscript.

\section{Ethics approval and consent to participate}

This study protocol was conducted in accordance with the Principles of the Declaration of Helsinki and the Declaration of Istanbul, and was approved by the ethics committee of the Osaka City University Graduate School of Medicine (No. 4009). Opt-out consent was obtained instead of written informed consent; i.e., we provided the patients with information explaining the proposed research project (the purpose, required individual data and duration of the study) by means of an information sheet or hospital website and gave them the opportunity to opt out.

\section{Consent for publication}

For publication of this manuscript, opt-out consent was obtained by means of an information sheet or hospital website.

\section{Competing interests}

The authors declare that they have no competing interests.

\section{Publisher's Note}

Springer Nature remains neutral with regard to jurisdictional claims in published maps and institutional affiliations.

\section{Author details}

'Department of Medical Devices, Osaka City University Hospital, Osaka, Japan. ${ }^{2}$ Department of Urology, Osaka City University Graduate School of Medicine, 1-4-3 Asahi-machi, Abeno-ku, Osaka 545-8585, Japan. ${ }^{3}$ Department of Medical Statistics, Osaka City University Graduate School of Medicine, Osaka, Japan.

Received: 23 November 2018 Accepted: 4 February 2019

Published online: 13 February 2019

\section{References}

1. Gloor J, Stegall M. ABO-incompatible kidney transplantation with and without splenectomy. Transplantation. 2006;82(5):720.

2. Shin E, Kwon SW, Yang WS, Baeck C, Yu H, Cho H, et al. Long-term outcomes of ABO-incompatible living donor kidney transplantation: a comparative analysis. Transplant Proc. 2015;47(6):1720-6.

3. Sonnenday CJ, Warren DS, Cooper M, Samaniego M, Haas M, King KE, et al. Plasmapheresis, CMV hyperimmune globulin, and anti-CD20 allow ABOincompatible renal transplantation without splenectomy. Am J Transplant. 2004:4(8):1315-22

4. Uchida J, Kuwabara N, Machida Y, Iwai T, Naganuma T, Kumada N, et al. Excellent outcomes of ABO-incompatible kidney transplantation: a singlecenter experience. Transplant Proc. 2012;44(1):204-9.

5. Wilpert J, Fischer KG, Pisarski P, Wiech T, Daskalakis M, Ziegler A, et al. Longterm outcome of $\mathrm{ABO}$-incompatible living donor kidney transplantation based on antigen-specific desensitization. An observational comparative analysis. Nephrol Dial Transplant. 2010;25(11):3778-86.

6. Yabu JM, Fontaine MJ. ABO-incompatible living donor kidney transplantation without post-transplant therapeutic plasma exchange. J Clin Apher. 2015;30(6):340-6

7. Lipshutz GS, McGuire S, Zhu Q, Ziman A, Davis R, Goldfinger D, et al. ABO blood type-incompatible kidney transplantation and access to organs. Arch Surg. 2011;146(4):453-8.

8. Montgomery RA, Locke JE, King KE, Segev DL, Warren DS, Kraus ES, et al. $\mathrm{ABO}$ incompatible renal transplantation: a paradigm ready for broad implementation. Transplantation. 2009;87(8):1246-55.

9. Segev DL, Simpkins CE, Warren DS, King KE, Shirey RS, Maley WR, et al. $\mathrm{ABO}$ incompatible high-titer renal transplantation without splenectomy or anti-CD20 treatment. Am J Transplant. 2005;5(10):2570-5.

10. Toki D, Ishida H, Setoguchi K, Shimizu T, Omoto K, Shirakawa H, et al. Acute antibody-mediated rejection in living ABO-incompatible kidney transplantation: long-term impact and risk factors. Am J Transplant. 2009; 9(3):567-77

11. Warren DS, Montgomery RA. Incompatible kidney transplantation: lessons from a decade of desensitization and paired kidney exchange. Immunol Res. 2010;47(1-3):257-64

12. Abu Jawdeh BG, Cuffy MC, Alloway RR, Shields AR, Woodle ES. Desensitization in kidney transplantation: review and future perspectives. Clin Transpl. 2014;28(4):494-507.

13. Rostaing L, Allal A, Del Bello A, Sallusto F, Esposito L, Doumerc N, et al. Treatment of large plasma volumes using specific immunoadsorption to desensitize ABO-incompatible kidney-transplant candidates. J Nephropathol. 2016:5(3):90-7.

14. Singh N, Pirsch J, Samaniego M. Antibody-mediated rejection: treatment alternatives and outcomes. Transplant Rev (Orlando). 2009:23(1):34-46.

15. Kim MH, Jun KW, Hwang JK, Kim Jl, Chung BH, Choi BS, et al. Risk factors for postoperative bleeding in ABO-incompatible kidney transplantation. Clin Transpl. 2015;29(4):365-72.

16. Takahashi K Saito K. ABO-incompatible kidney transplantation. Transplant Rev (Orlando). 2013;27(1):1-8. 
17. Hanafusa N, Hamasaki Y, Kawarasaki H, Kido R, Shibagaki Y, Ishikawa A, et al. The effect of different apheresis modalities on coagulation factor XIII level during antibody removal in ABO-blood type incompatible living related renal transplantation. Transfus Apher Sci. 2013;49(2):254-8.

18. Basic-Jukic N, Kes P, Glavas-Boras S, Brunetta B, Bubic-Filipi L, Puretic Z. Complications of therapeutic plasma exchange: experience with 4857 treatments. Ther Apher Dial. 2005;9(5):391-5.

19. Song EY, Yoon JH, Lee JW, Park CW, Kwon SW, Kim DW, et al. Establishment of a national on-line registry for apheresis in Korea. Transfus Apher Sci. 2008; 38(2):93-100.

20. Ohkubo A, Okado T. Selective plasma exchange. Transfus Apher Sci. 2017; 56(5):657-60.

21. Kawabe M, Yamamoto I, Katsuma A, Hayashi N, Komatsuzaki Y, Nakada Y, et al. Successful treatment of myeloma cast nephropathy using bortezomibbased chemotherapy plus selective plasma exchange. CEN Case Rep. 2016; 5(2):232-7.

22. Nakae H, Fukuda H, Okuyama M, Igarashi T. Selective plasma exchange for critically ill patients accompanied with thrombocytopenia. Ther Apher Dial. 2016;20(4):339-41.

23. Nasu K, Hanafusa N, Nangaku M. Selective plasma exchange can reduce auto-antibodies in patients with bullous pemphigoid without affecting factor XIII and fibrinogen. J Clin Apher. 2017;32(6):589-91.

24. Ohkubo A, Okado T, Kurashima N, Maeda T, Miyamoto S, Nakamura A, et al. Removal kinetics of antibodies against glutamic acid decarboxylase by various plasmapheresis modalities in the treatment of neurological disorders. Ther Apher Dial. 2014:18(3):231-7.

25. Kim YC, Yu MY, Lee JP, Lee H, Min SI, Ha J, et al. The effect of desensitization therapy in kidney transplantation. Clin Exp Nephrol. 2018; 22(1):179-87.

26. Morath C, Becker LE, Leo A, Beimler J, Klein K, Seckinger J, et al. ABOincompatible kidney transplantation enabled by non-antigen-specific immunoadsorption. Transplantation. 2012;93(8):827-34.

27. Tyden G, Donauer J, Wadstrom J, Kumlien G, Wilpert J, Nilsson T, et al. Implementation of a protocol for ABO-incompatible kidney transplantation-a three-center experience with 60 consecutive transplantations. Transplantation. 2007;83(9):1153-5.

28. Uchida J, Iwai T, Nishide S, Kabei K, Kuwabara N, Yamasaki T, et al. Acute cellular rejection in ABO-incompatible renal transplant recipients receiving rituximab is associated with delayed-onset neutropenia. Ann Transplant. 2017;22:455-62.

29. Ohkubo A, Kurashima N, Nakamura A, Miyamoto S, limori S, Rai T. Solute removal capacity of high cut-off membrane plasma separators. Ther Apher Dial. 2013;17(5):484-9.

30. Ohkubo A, Okado T, Kurashima N, Maeda T, Arai S, Miyamoto S, et al. Removal characteristics of immunoglobulin $\mathrm{G}$ subclasses by conventional plasma exchange and selective plasma exchange. Ther Apher Dial. 2015; 19(4):361-6.

31. Ohkubo A, Okado T, Miyamoto S, Hashimoto Y, Komori S, Yamamoto M, et al. Fibrinogen reduction during selective plasma exchange due to membrane fouling. Ther Apher Dial. 2017;21(3):232-7.

Ready to submit your research? Choose BMC and benefit from:

- fast, convenient online submission

- thorough peer review by experienced researchers in your field

- rapid publication on acceptance

- support for research data, including large and complex data types

- gold Open Access which fosters wider collaboration and increased citations

- maximum visibility for your research: over $100 \mathrm{M}$ website views per year

At BMC, research is always in progress.

Learn more biomedcentral.com/submissions 